\title{
USING PICTURE EXCHANGE COMMUNICATION SYSTEM TO IMPROVE SPEECH UTTERANCE AMONG CHILDREN WITH AUTISM
}

\author{
Widuri Jusoh ${ }^{\mathrm{a}}$, Rosadah Abd Majid ${ }^{\mathrm{b}}$ \\ aSekolah Kebangsaan Datu'Hashim, Pengkalan Chepa, 16100, Kota Bharu, Kelantan, Malaysia \\ ${ }^{b}$ National University of Malaysia,43600 Bangi, Selangor, Malaysia. \\ E-mail : widurijusoh@gmail.com
}

\begin{abstract}
Picture Exchange Communication System is a common augmentative communication system used on children with Autism Spectrum Disorder (ASD), which is one of the categories of developmental problems in social interaction, communication and behavior patterns. The aim of this study is to see an increase in the utterance of the word by students with autism using PECS. This study is an action research using quantitative descriptive on data collection. Observations were implemented over a period of four weeks to see the effectiveness of PECS using cartoon picture cards and cards real pictures to enhance the utterance of two primary school autism students. From the result shown, the application of PECS successfully stimulates utterance among the students. This study is expected to enhance the communication and social interaction development of children with autism and other children who have difficulty mastering the language.
\end{abstract}

Keywords: Autism Students, utterances, PECS

Autism is a disability which is characterized by a breakdown in communication, social interaction, sensory disturbances, and emotional behavior. Kathleen et.al (2002) and Hybels and Weaver (2001) defines communication as a process of creating and sharing meanings, feelings and ideas in speech, writing, group interaction or public speeches. This process involves individuals and their interaction with the elements of the context, message, channel, noise (interference) and feedback prevail. It clearly shows that communication involves interaction between two individuals as a transmitter and receiver of information and produces an effect. Communication is also a process of teachers sharing experiences with his students (Abdullah Hassan and Ainon Mohd, 2002). According to the Kamus Dewan of fourth edition, speech means something is said or mentioned. In this study, it is seen as a way for students with autism to convey or deliver their message by uttering words they have heard or learned. The increase in their word speech has been seen as a guide in how well did they acquire their social communication skills. Picture Exchange Communication System (PECS) is an alternative way of autism children were taught to communicate using PECS flash cards. According to Frost and Bondy (2002), PECS is one of the primary approaches in teaching communication skills by using pictures. Thus, this approach is particularly suitable for students with Autism Spectrum Disorder problems (ASD).
PECS is a program that consists of six phases. Each has the role to develop children's speaking skills and to enable them to communicate (Spence-Cochran and Pearl, 2012). Each phase undertaken should be done in sequence. The first phase, students learn spontaneously to express their need with picture cards. Students will be using one card at a time. In the second phase, teachers will add on vocabulary by adding the number of cards that are used, with the same technique. The third phase, teachers teach students to identify the cards and help them to put it on the white board. By phase four, the teacher teaches the students basic sentence structure using sentences. In the final fifth and sixth phase, the teacher adds on vocabulary with adjectives and other words. The researcher used only phase one to phase three since the students has a very limited of words.

Children with autism may have difficulty with language skills and to receive information given to them. They also have difficulty with non-verbal communication such as hand gestures, eye contact and facial expressions (National Institute on Deafness and Other Communication Disorder, 2016). At least $40 \%$ of children with autism are unable to speak. About $25 \%$ to $30 \%$ of children with autism are able to speak at the age of 12 to 18 months and then lost this ability. They are also only able to speak after 4 or 5 years or more. According to Tien (2008), PECS is an effective intervention for improving the communication skills among participants with ASD. The question of whether 
the use of PECS can improve speech word in autistic students need to be researched. As much as 35\%-55\% of individuals with Autism, never had communication skills (Cafiero and Meyer, 2008). In this study, the participants have limited amount of speech word for which they have difficulties to express their wishes. Therefore, this study was undertaken to see an increase in speech words uttered by the student with autism using PECS.

\section{METHOD}

This study is consists of two rolling action. Therefore, this is an action research using a quantitative approach based on the behavior of conditioning theory expounded by Ivan Pavlov (1849) and combined with model studies Kemmis and McTaggart (1988). The method of collecting data was by using a checklist which was done three times a week during the Bahasa Melayu lesson for an hour per session. It was implemented in stages over four weeks with a different set of PECS every two weeks involving the two loops of study. In the first and second week of study, cartoon PECS (PECS 1) was provided during the process. Next on the third and fourth weeks which was the second loop, PECS with real pictures (PECS 2) was provided. The data on the number of speech words said by the participants for both loops were recorded. The selection of participants was by purposive sampling (Noraini, 2010). The participants were two boys aged 8 and 10 years old, from the Special Education Integration Programme in primary schools which have had communication problem in the classroom. They were labelled as Student A and Student B to facilitate the analysis of the findings. A total of ten cards images were used in Table 1.
Figure 1: Two rolling action research based Action Research Model Kemmis \& Mc Taggart (1988)

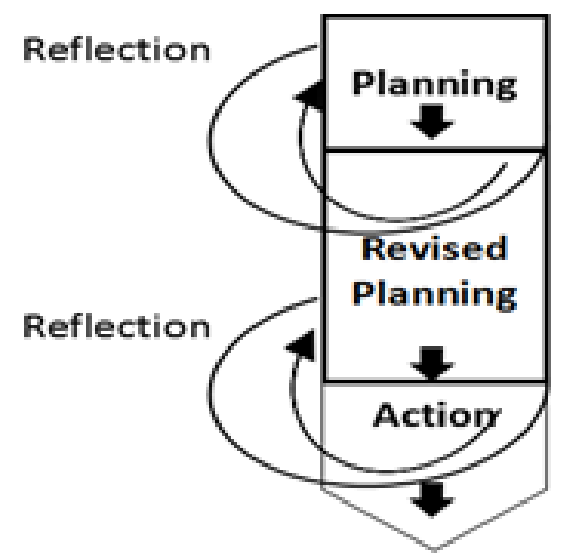

In the first loop of this study, the researchers had used a one to one coaching with the participants. The participants were asked to choose a cartoon picture and showed it to the researcher. The researcher will then read out the words accordingly while the participants were encouraged to repeat the words they heard. Each successful attempt by the participants, will be recorded by the researcher. This approach will run for two weeks. At the end of two weeks of PECS 1, the results showed that the participants did not achieve the desired objective of uttering 5 words from the 10 words given. Hence in the second loop of this study, the researchers used the stimulus of ten pictures of the same object but changing cartoon pictures into real picture (PECS 2). The same guidance on the first loop was executed for two weeks during the third and fourth weeks. At the end of the implementation process of the second loop, the recorded data will be compared with the data obtained in the first loop.

\section{FINDINGS AND DISCUSSION}

\section{Findings}

The findings of this study can be extracted from Table 1 below.

Table 1: Data Collection of Speech Word

\begin{tabular}{|c|c|c|c|c|c|c|c|c|}
\hline \multirow[b]{3}{*}{ Picture } & \multicolumn{4}{|c|}{ Student A } & \multicolumn{4}{|c|}{ Student B } \\
\hline & \multicolumn{2}{|c|}{ PECS 1} & \multicolumn{2}{|c|}{ PECS 2} & \multicolumn{2}{|c|}{ PECS 1} & \multicolumn{2}{|c|}{ PECS 2} \\
\hline & Week 1 & Week 2 & Week 3 & Week 4 & Week 1 & Week 2 & Week 3 & Week 4 \\
\hline Drink & & & & & & & & \\
\hline Eat & 1 & & & & 1 & & & \\
\hline Canteen & & 1 & & & 1 & & & 1 \\
\hline Toilet & & 1 & & & & & & 1 \\
\hline Trash & & & & 1 & & & 1 & 1 \\
\hline $\begin{array}{c}\text { Coloured } \\
\text { pensil }\end{array}$ & & & 1 & 1 & & & & \\
\hline TV & & & 1 & 1 & & & 1 & 1 \\
\hline $\mathrm{Cd}$ & & & 1 & 1 & & 1 & 1 & 1 \\
\hline PJ tshirt & & & & 1 & & & 1 & 1 \\
\hline Watch & & & & & & & & \\
\hline Total & 1 & 2 & 3 & 5 & 2 & 1 & 4 & 6 \\
\hline
\end{tabular}


Figure 2: Word Speech Enhancement Graph Using PECS

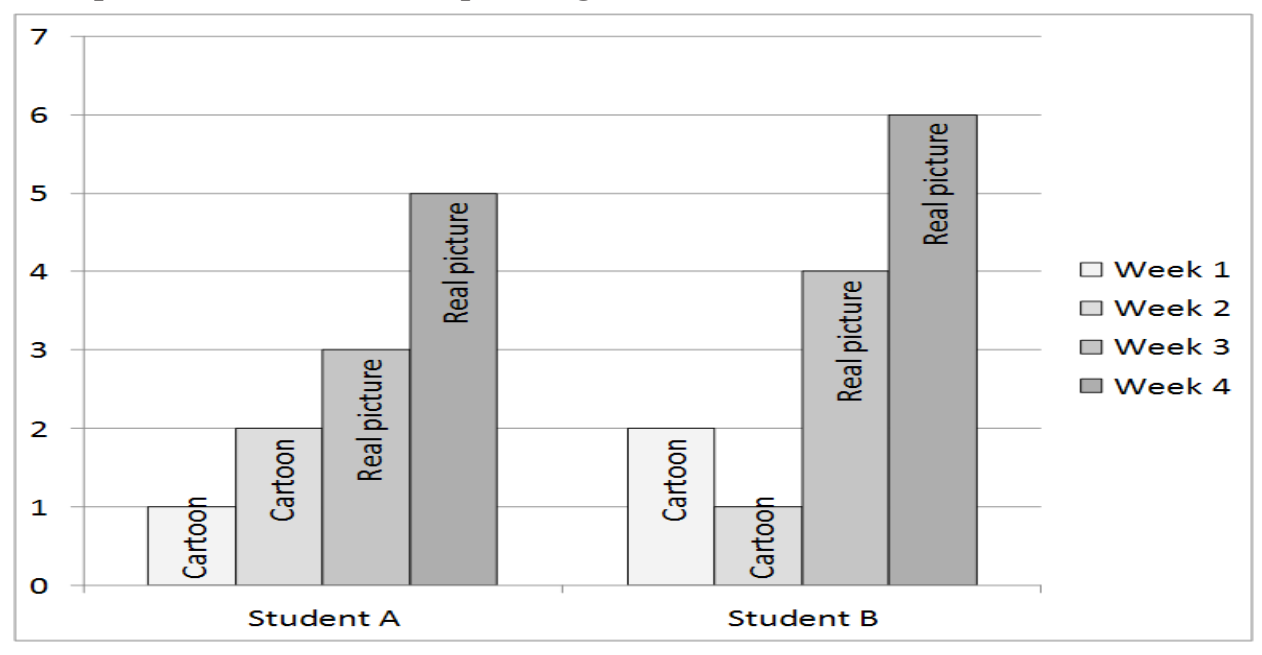

Table 1 shows an increase in speech word for student A and student B after the implementation of PECS. For students A, there was a continued improvement from week one to week four. Starting with PECS 1, the word uttered was "eat", then it was increased by two speech-word which is was "eat" and "toilet" in the second week, it increased to three utterance of the word, namely "coloured pencil", "tv" and "cd "in the third week after using PECS 2. In the last week of the fourth week, the uttered word continued to increase, student A managed to utter five words which are the word "trash", "coloured pencil", "tv", "cd" and "pj shirt", For students B, in the first week, there were two word utterances that were recorded which were "eat" and "canteen". However in the second week, the student was only able to utter the word "cd". Further improvement were see in the third week after PECS 2 was given, B student was able to utter four words which were "trash", "tv", "d", and "pj shirt". In the final weeks, there was a sharp increase in the word utterance by student B which was six words of "canteen", "toilet", "trash", "tv", "cd" and "pj shirt". The data collected from the studies that had been conducted showed that the utterance of the words by students with autism can be improved by application of PECS 2 and the teachers may be able to carry out the process of the PDP effectively.

\section{Discussion}

Based on recent research findings, it is proven that the use of PECS, using stiff card image is more effective in improving the speech for students with autism. Similar prior studies conducted by Lerna, Anna Esposito, Dalila Conson, Massimiliano Massagli and Angelo (2014) all indicated that PECS used on children with Autism Spectrum Disorder (ASD) increases their abilities in areas such as communication skills, asking skills and cooperative games and activities. This result has proven PECS to have a positive impact towards communication skills (Anna Lerna et.al, 2014). In fact this findings contradicts with researches made in Philippines, Flippin et.al (2010) stating that PECS only offers an average hike in communication skills among autistic children. However, research conducted by Sulzer Azaroff, Hoffman, Horton, Bondy and Frost (2009) confirms PECS to be a very effective learning technique in communication skills that is also beneficial to individuals with people having speech problems and even for the mute. According to Kasari et al. (2012), socio-communicative skills at an early age are very important. This is because attention must be given since young. This is indeed affectsed the learning level of the child as set out in the behavioral theory expounded by Ivan Pavlov (1849).The findings showed that 170 of the 173 children who participated in the PECS study or other picture exchange communication interventions showed improvement in their ability to make a request. It shows that PECS is an effective approach in changing not only the behavior of children with autism but also children with other learning disabilities (Lancioni, 2007). Therefore, the proposed PECS can also be used for students who have stutter problems. Apart from that, PECS is suitable for hyperactive children in behavior management. These interventions can be combined with rewards, or combined with token to attract children with autism to communicate.

\section{CONCLUSION AND SUGGESTION}

Through the application of PECS on the two autism students, there is an increase in their word speech after two phases of intervention. The usage of PECS in teaching and learning can enhance the utterance of the word and allow students to focus more on what is taught by the teacher. Hence, this study has implications for 
teachers of special education in particular to apply the PECS in PDP. The use of PECS is one of the important strategies to address the problem of communication and learning disabilities in students and children with

\section{REFERENCES}

Abdullah Hassan \& Ainon Mohd. (2002). Kemahiran interpersonal untuk guru. Pahang: PTS Publications \& Distributor Sdn. Bhd

Cafiero, J. M. (2008). The effect of an augmentative communication intervention on the communication, behavior, and academic program of an adolescent with autism. Focus on Autism and Other Developmental Disabilities, 16, $179-189$.

Flippin, M. , Reszka , S. , \& Watson , L. R .(2010). Effectiveness of the Picture Exchange Communication System(PECS) on communication and speech for children with autism spectrum disorders: A meta-analysis. American Journal of Speech- Language Pathology, 19, 178 - 195 .

Frost, L., \& Bondy, A. (2002). PECS: Picture Exchange Communication System Training Manual (2nd ed.) . Cherry Hill, NJ: Pyramid Educational Consultants Inc.

Kasari, C., Gulsrud, A., Freeman, S., Paparella, T. And Hellemann, G., (2012), Longitudinal follow-up of children with autism receiving targeted interventions on joint attention and play. Journal of the American Academy of Child and Adolescent Psychiatry, 51, 487-495.

Kathleen S. Verderber, Rudolph F. Verderber \& Deanna D. Sellnow. (2002). Communicate 14th Edition. ISBN-13: 978-0840028167. ISBN10: 0840028164. Wadsworth Publishing;

14 edition (January 1, 2013) autism. However, the cooperation between teachers and parents is strongly needed in order to encourage them to improve their communication skills and to maintain the effectiveness of educational interventions.

Lancioni, G. E., O’Reilly, M. F., Cuvo, A. J., Singh,N. N., Sigafoos, J.,\&Didden, R. (2007). PECS and VOCAs to enable students with developmental disabilities to make requests: An overview of the literature. Research in Developmental Disabilities, 28, 468488.

Lerna, A., Esposito, D.,Conson, M., Russo, L. And Massagli, A., 2012, Socialcommunicative effects of the Picture Exchange Communication System (PECS) in autism spectrum disorders. International Journal of Language and Communication Disorders, 47, 609-617.

Lerna, Anna, Esposito, Dalila Conson, Massimiliano Massagli, Angelo (2014). Long-term effects of PECS on social-communicative skills of children with autism spectrum disorders: a follow-up study. International journal of language \& communication disorders / Royal College of Speech \& Language Therapists. DOI: 10.1111/1460-6984.12079

Noraini Idris. 2010. Penyelidikan dalam pendidikan. Kuala Lumpur.McGraw Hill (Malaysia) Sdn.Bhd

Sulzer-Azaroff, B., Hoffman, A. O., Horton, C. B., Bondy, A., \& Frost, L. (2009). The Picture Exchange Communication System (PECS): what do the data say? Focus on Autism and Other Developmental Disabilities, 24(2), 89- 103.

Tien, K. C. (2008). Effectiveness of the Picture Exchange Communication System as a functional communication intervention for individuals wit $\mathrm{h}$ autism spectrum disorders: A practice-based research synthesis. Education and Training in Developmental Disabilities, 43, 67-76. 